УДК: 547.913: 543.544.45

\title{
КОМПОНЕНТНЫЙ СОСТАВ ЭФИРНОГО МАСЛА SATUREJA SUBDENTATA ВOISS. В ПРИРОДНОЙ И ИНТРОДУКЦИОННЫХ ПОПУЛЯЦИЯХ ИЗ ФЛОРЫ ДАГЕСТАНА
}

\author{
() Г.К. Раджабов ${ }^{\text {*** }}$, А.М. Алиев ${ }^{1,2}$, Ф.А. Вагабова ${ }^{1}$, А.М. Мусаев \\ ${ }^{1}$ Горный ботанический сад Дагестанского научного центра Российской \\ академии наук, ул. Ярагского, 75, Махачкала, 367000 (Россия), \\ e-mail: chemfarm@mail.ru \\ ${ }^{2}$ Институт физики Дагестанского научного центра Российской академии \\ наук, ул. Ярагского, 94, Махачкала, 367000 (Россия)
}

\begin{abstract}
Систематический статус исследуемого вида и его фрагментарный ареал совместно с полиморфностью вида в пределах его природного распространения вызывают интерес к изучению трендов изменчивости по компонентному составу эфирных масел вдоль средовых градиентов.

Исходя из того, что дагестанская часть ареала этого вида ранее совершенно не изучена по компонентному составу эфирного масла, в данной работе была поставлена цель получить представление о компонентном составе эфирного масла надземной части «типичной» популяции Satureja subdentata Boiss. из среднегорья.

Методом хромато-масс-спектрометрии исследован компонентный состав эфирных масел природных и культурных образцов S. subdentata, полученных гидродистилляцией надземной части растения.

Идентифицировано 53 компонента эфирного масла из 61 обнаруженного.

Так, выявлено снижение содержания монотерпенов и их производных и увеличение сесквитерпенов и их производных при сравнении природного образца с Куппинского перевала (1000 м над у.м.) с их образцами на Гунибском (1730 м над у.м.) и Цудахарском (1100 м над у.м.) экспериментальных участках. Также отмечается разнонаправленное действие высоты места сбора сырья над уровнем моря на количественное содержание отдельных компонентов эфирного масла.
\end{abstract}

Ключевые слова: Satureia subdentata Boiss., эфирное масло, аппарат Клевенджера, хромато-масс-спектрометрия.

\section{Введение}

Чабер (Satureja) относится к семейству яснотковых (Lamiaceae). Виды рода Satureja распространены на территории Средиземноморского региона Европы, Восточной Азии, Северной Африки, Канарских островов и Южной Америки [1, 2]. В роду Satureja насчитывают до 200 видов [3]. Во флоре Дагестана род Satureja представлен 3 видами [4]. Satureia subdentata Boiss. - наиболее известный из многолетних видов.

Раджабов Гаджи Камалудинович - научный сотрудник лаборатории фитохимии и медицинской ботаники, e-mail: chemfarm@mail.ru

Алиев Аслан Мурадалиевич - старший научный сотрудник лаборатории фитохимии и медицинской ботаники, e-mail: aslan4848@yahoo.com

Вагабова Фазина Аскералиевна - кандидат технических наук, старший научный сотрудник лаборатории фитохимии и медицинской ботаники,

e-mail: fazina@mail.ru

Мусаев Абдулахид Магомедович - и.о. заместителя директора по научной работе, и.о. заведующего лабораторией фитохимии и медицинской ботаники, e-mail: musaev-58@ list.ru
Многие виды Satureja являются важным товаром для экспорта. Так, в Турции ежегодно собирают и продают до 1000 тонн сухой продукции под названием Sivri kekik [5]. В сухом и свежем виде растения Satureja используются в кулинарии, медицине, ликеро-водочной и парфюмерно-косметической продукции [6-11].

Содержание карвакрола и тимола в эфирном масле определяют его применение в медицине как антисептического, бактерицидного, фунгицидного средства. Карвакрол определяет характерный жгу-

\footnotetext{
"Данная статья имеет электронный дополнительный материал (приложение), который доступен читателям на сайте журнала. DOI: 10.14258/jcprm.2017011390s

Автор, с которым следует вести переписку.
} 
чий вкус масла и его специфический запах, однако его количество, как и содержание других компонентов (тимола, пара-цимола, гамма-терпинена и др. соединений), весьма непостоянно, что неоднократно отмечалось в публикациях $[8,12]$. Установлена высокая активность эфирных масел, оказывающих угнетающее действие на граммположительные бактерии (до 10 видов, в том числе на синегнойную палочку и золотистый стафилококк) и до 7 видов грибковых патогенных организмов [13], на возбудителя сосудистого бактериоза капусты [14] и шистосомного церкариоза [15].

Дагестанские виды рода Satureja до сих пор не изучены с точки зрения химического состава. Наши исследования химического состава и влияния различных факторов среды на накопление биологически активных веществ в природных и интродуцированных образцах некоторых дагестанских видов Satureja являются первыми [16]. Исследование особенностей накопления эфирных масел вдоль высотного градиента в условиях Дагестана в сырье $S$. subdentata Boiss., их состава представляет большой научный и практический интерес.

Целью настоящей работы явилось изучение изменчивости содержания эфирного масла надземной части природных и культурных образцов $S$. subdentata из флоры Дагестана в зависимости от высоты над уровнем моря места произрастания сырья.

\section{Экспериментальная часть}

Надземная часть S. subdentata Boiss. для получения эфирного масла была собрана в период цветения (август 2014 г.) из природных (Куппинский перевал 1000 м. над у. м.) и экспериментальных популяций: ГЭБ (Гунибская экспериментальная база, 1730 м. над у. м.) и ЦЭБ (Цудахарская экспериментальная база, 1100 м. над у. м.). Живые растения были пересажены с Куппинского перевала на эти экспериментальные участки в 2012 г.

Собранное сырье высушили в тени до воздушно-сухой массы. Образцы были определены заведующим лабораторией фитохимии и медицинской ботаники ГорБС ДНЦ РАН, А.М. Мусаевым. Гербарные образцы хранятся в коллекции гербарий ГорБС ДНЦ РАН. Эфирное масло получали методом водной дистилляции на аппарате Клевенджера в течение 2 ч [17].

Эфирное масло было исследовано методом хромато-масс-спектрометрии на газовом хроматографе Shimadzu GC-2010 с квадрупольным масс-спектрометром Shimadzu QP2010plus в качестве детектора. Была использована колонка Supelco SLBTM-5ms $(30 \mathrm{~m} \times 0,25 \mathrm{~mm} \times 0,25 \mu \mathrm{m})$ в режиме «split». Газ-носитель - гелий с постоянным потоком 1 мл/мин. В хроматограф вводили 1 мкл разбавленного в 1000 раз в гексане эфирного масла с разделением потока $40: 1$. Температура испарителя $250{ }^{\circ} \mathrm{C}$. Температура колонки $60{ }^{\circ} \mathrm{C}(4$ мин), 60 $150{ }^{\circ} \mathrm{C}\left(10^{\circ} \mathrm{C} /\right.$ мин $), 150-250{ }^{\circ} \mathrm{C}\left(5^{\circ} \mathrm{C} /\right.$ мин $), 250^{\circ} \mathrm{C}$ (3 мин). Температура интерфейса между газовым хроматографом и масс-селективным детектором $250^{\circ} \mathrm{C}$. Температура источника ионов $250^{\circ} \mathrm{C}$. Энергия ионизирующих электронов 70 эВ. Данные собирали со скоростью 2500 а.е.м./сек в диапазоне масс 45-500 а.е.м. Идентификация компонентов проводилась с использованием библиотек масс-спектров NIST08 и FFNSC. Соединение считали идентифицированным при совпадении масс-спекторов на 95\% и выше [18-22].

\section{Обсуждение результатов}

Выход эфирного масла из надземной части $S$. subdentata составил на воздушно-сухое сырье для образца с Куппинского перевала 1000 м. над у. м. - 0,52\%, с ЦЭБ (Куппинский перевал) - 0,48\% и с ГЭБ (Куппинский перевал) - 0,37\%.

Всего в составе эфирных масел обнаружено 61 вещество, из них идентифицировано 53 компонента. Поскольку некоторые из компонентов содержатся в исследованных образцах в следовых количествах, из-за этого в ходе хромато-масс-спектрометрического эксперимента они дают низкого качества масс-спектры, и поэтому не могут быть достоверно идентифицированы. Что касается основных компонентов, то все они легко опознаются по характерным масс-спектрам и линейным индексам удерживания, приведенным в руководстве [22]. Основная часть эфирных масел представлена моно- и сесквитерпеноидами. Основными компонентами эфирных масел всех образцов S. subdentata являются: $\beta$-оцимен; $n$-цимол; лимонен; $m p a н c-$ $\beta$-оцимен; $\gamma$-терпинен; борнеол; карвакрол; транс-кариофиллен; гермакрен $\mathrm{D}$; бициклогермакрен. Компоненты трициклен и $\alpha$-гуржунен содержится только в образце, собранном на ЦЭБ Горного ботанического сада ДНЦ РАН (пересаженные с Куппинского перевала). 
В результате исследования установлено, что содержание компонентного состава в образцах эфирного масла надземной части S. subdentata Boiss. из флоры Дагестана колеблется от 49 до 52 компонентов. При этом отмечено, что наибольшее количество компонентов содержится в образце эфирного масла из надземной части S. subdentata, пересаженного с Куппинского перевала на ЦЭБ (52 компонента) (табл., электронное приложение, рис. 1-3).

Компонентный состав эфирных масел Satureja subdentata Boiss. в природной и интродукционной популяциях флоры Дагестана, сбор 2014 г.

\begin{tabular}{|c|c|c|c|c|}
\hline \multirow[t]{2}{*}{ Название компонента } & \multirow[t]{2}{*}{ Индекс удерживания } & \multicolumn{3}{|c|}{$\begin{array}{c}\text { Содержание компонентов в \% от цельного масла } \\
\text { Satureja subdentata Boiss. }\end{array}$} \\
\hline & & $1 *$ & $2 * *$ & $3 * * *$ \\
\hline 1 & 2 & 3 & 4 & 5 \\
\hline \multicolumn{5}{|c|}{ Монотерпень и их производнье } \\
\hline Трициклен & 923 & & 0,11 & \\
\hline$\alpha$-туйен & 927 & 0,70 & 0,57 & 0,60 \\
\hline$\alpha$-пинен & 933 & 3,09 & 2,78 & 2,86 \\
\hline Камфен & 953 & 2,67 & 2,08 & 2,09 \\
\hline Сабинен & 972 & 0,37 & 0,34 & 0,32 \\
\hline$\beta$-оцимен & 976 & 1,89 & 3,29 & 5,79 \\
\hline Мирцен & 991 & 1,57 & 4,11 & 2,07 \\
\hline$\alpha$-фелландрен & 1007 & 0,25 & 0,30 & 0,38 \\
\hline$\alpha$-терпинен & 1018 & 2,04 & 1,45 & 1,45 \\
\hline$n$-цимол & 1025 & 10,91 & 6,75 & 5,51 \\
\hline Лимонен & 1030 & 5,88 & 5,93 & 6,99 \\
\hline транс- $\beta$-оцимен & 1041 & 4,21 & 4,48 & 5,97 \\
\hline$\gamma$-терпинен & 1058 & 6,95 & 5,78 & 7,60 \\
\hline Терпинолен & 1086 & 0,67 & 0,48 & 0,38 \\
\hline транс-сабинен гидрат & 1099 & 0,75 & 0,69 & 0,44 \\
\hline Линалоол & 1101 & 0,51 & 1,11 & 0,80 \\
\hline 4-транс, 6-ц̧ис-аллоцимен & 1128 & 0,43 & 0,45 & 0,69 \\
\hline ичис-вербенол & 1141 & 0,25 & 0,12 & 0,08 \\
\hline Камфора & 1149 & 0,27 & 0,26 & 0,19 \\
\hline Борнеол & 1173 & 9,31 & 7,68 & 6,87 \\
\hline Терпинен-4-ол & 1180 & 4,86 & 2,97 & 2,20 \\
\hline$\alpha$-терпинеол & 1195 & 1,36 & 0,98 & 0,58 \\
\hline uңис-дигидрокарвон & 1198 & 0,38 & 0,35 & 0,32 \\
\hline транс-дигидрокарвон & 1215 & 0,38 & 0,29 & 0,37 \\
\hline транс-карвеол & 1223 & 0,12 & & 0,06 \\
\hline Тимол метиловый эфир & 1239 & 0,95 & 1,51 & 1,89 \\
\hline Карвон & 1246 & 0,88 & 0,79 & 0,75 \\
\hline Тимол & 1293 & 0,36 & 0,11 & 0,10 \\
\hline Карвакрол & 1300 & 13,05 & 9,89 & 8,61 \\
\hline Карвакрил ацетат & 1365 & 0,22 & 0,11 & 0,11 \\
\hline \multicolumn{5}{|c|}{ Сесквитерпены и их производные } \\
\hline Лонгициклен & 1367 & & 0,08 & 0,07 \\
\hline$\alpha$-копаен & 1375 & 0,17 & 0,22 & 0,21 \\
\hline$\beta$-боурбонен & 1382 & 0,93 & 1,22 & 1,26 \\
\hline$\alpha$-кубебен & 1391 & 0,26 & 0,36 & \\
\hline$\beta$-кубебен & 1394 & 0,32 & 0,35 & 0,33 \\
\hline$\alpha$-гуржунен & 1406 & & 0,07 & \\
\hline транс-кариофиллен & 1424 & 2,22 & 2,32 & 5,40 \\
\hline Аромадендрен & 1438 & 0,98 & 1,02 & 0,45 \\
\hline$\alpha$-аморфен & 1440 & 0,28 & 0,41 & 0,33 \\
\hline Изогермакрен D & 1447 & 0,14 & 0,14 & 0,12 \\
\hline$\alpha$-гумулен & 1454 & 0,19 & 0,28 & 0,29 \\
\hline 9-эпи-транс-кариофиллен & 1464 & 0,21 & 0,24 & 0,20 \\
\hline Гермакрен D & 1480 & 2,46 & 6,45 & 7,47 \\
\hline Виридифлорен & 1491 & 0,71 & 0,90 & 0,50 \\
\hline Бициклогермакрен & 1497 & 4,63 & 8,83 & 6,76 \\
\hline транс- $\beta$-фарнесен & 1500 & 2,94 & 2,67 & 3,44 \\
\hline
\end{tabular}


Окончание таблиць

\begin{tabular}{l|c|c|c|c}
\hline \multicolumn{1}{c|}{1} & 2 & 3 & 4 & 5 \\
\hline uцс- $\alpha$-бисаболен & 1508 & 0,11 & 0,13 & 0,15 \\
иис- $\gamma$-бисаболен & 1511 & 0,23 & 0,18 & 0,15 \\
$\gamma$-кадинен & 1512 & 0,15 & 0,16 & 0,15 \\
$\delta$-кадинен & 1518 & 0,32 & 0,51 & 0,50 \\
(-)-спатуленол & 1536 & & 0,21 & 0,13 \\
Спатуленол & 1576 & 3,69 & 2,89 & 2,30 \\
Кариофиллен оксид & 1587 & 0,94 & 0,69 & 0,83 \\
\hline Общее содержание монотерпеноидов & $\mathbf{7 5 , 2 8}$ & $\mathbf{6 5 , 7 6}$ & $\mathbf{6 6 , 0 7}$ \\
\hline Общее содержание сесквитерпеноидов & $\mathbf{2 1 , 8 8}$ & $\mathbf{3 0 , 3 3}$ & $\mathbf{3 1 , 0 4}$ \\
\hline Не идентифицированные вещества & $\mathbf{2 , 8 4}$ & $\mathbf{3 , 9 1}$ & $\mathbf{2 , 8 9}$ \\
\hline
\end{tabular}

Примечания: * Место, высота, дата сбора: Дагестан, Куппинский перевал, 1000 метров над уровнем моря, 26 августа 2014 г.; ** Место, высота, дата сбора: интродуцент, Дагестан, Цудахарская экспериментальная база Горного ботанического сада ДНЦ РАН (пересаженные с Куппинского перевала), 1100 метров над уровнем моря, 13 августа 2014 г.; ***Место, высота, дата сбора: интродуцент, Дагестан, Гунибская экспериментальная база Горного ботанического сада ДНЦ РАН (пересаженные с Куппинского перевала), 1730 метров над уровнем моря, 27 августа 2014 г.

По данным анализа в сырье $S$. subdentata нами были выявлены закономерности в изменчивости содержания эфирного масла с происхождением и места сбора сырья вдоль высотного градиента.

Так, при сравнении результатов количественного содержания компонентов эфирного масла образцов S. subdentata, пересаженных с Куппинского перевала на экспериментальные базы ЦЭБ (1100 м над У.м.) и ГЭБ (1730 м. над у. м.) из природной популяции (Куппинский перевал, 1000 м. над у.м.), обнаружено снижение содержания монотерпеноидов и увеличение сесквитерпеноидов. На наш взгляд, это, возможно, связано с их ролью мембранностабилизаторов и является реакцией на повышение содержания ультрафиолетового излучения в солнечной радиации вдоль высотного градиента.

В интродукционных популяциях S. subdentata с набором высоты над уровнем моря общее количественное содержание компонентов (монотерпеноиды и сесквитерпеноиды) эфирного масла существенно не меняется.

Выявлена четкая тенденция к повышению количественного содержания 12 компонентов ( $\beta$-оцимен; $\alpha$-фелландрен; лимонен; транс- $\beta$-оцимен; 4-транс, 6-цуис-аллоцимен; тимол метиловый эфир; $\beta$-боурбонен; $\alpha$-кубебен; транс-кариофиллен; $\alpha$-гумулен; гермакрен D; изис- $\alpha$-бисаболен) и к понижению количественного содержания 21 компонента (сабинен; $\alpha$-терпинен; $n$-цимол; терпинолен; транс-сабинен гидрат; циисвербенол; камфора; борнеол; терпинен-4-ол; $\alpha$-терпинеол; цис-дигидрокарвон; транс-карвеол; карвон; тимол; карвакрол; карвакрил ацетат; лонгициклен; изогермакрен D; циис- $\gamma$-бисаболен; (-)-спатуленол; спатуленол) эфирного масла с набором высоты над уровнем моря.

\section{Выводы}

Таким образом, нами впервые во флоре Дагестана были изучены образцы надземной части травы S. subdentata. Выход эфирного масла S. subdentata варьируется - от 0,37 до 0,52\%, что характеризуется географической изменчивостью. Наибольший выход эфирного масла получен из природного образца, собранного с Куппинского перевала 1000 м. над у. м. (0,52\%).

Методом хромато-масс-спектрометрии обнаружен 61 компонент, и из них идентифицировано 53 (монотерпены и их производные - 30; сесквитерпены и их производные - 23).

Но качественный состав основных компонентов эфирного масла остается почти постоянным, изменяется их количественное содержание в зависимости от географической приуроченности.

Результаты проделанной работы свидетельствуют о существенных изменениях, происходящих в количественном содержании компонентов эфирного масла S. subdentata Boiss. в культуре по сравнению с природным образцом. Например, в образцах эфирных масел интродукционных популяций количественное содержание монотерпенов и их производных понижается, а сесквитерпенов и их производных повышается по сравнению с природой. Также выявлено разнонаправленное действие высотного градиента на изменчивость количественного содержания отдельных компонентов эфирного масла.

Работа выполнена с использованием уникальной научной установки «Система экспериментальных баз, расположенных вдоль высотного градиента» (УНУ СЭБ ГорБС ДНЦ РАН). 


\section{Список литературы}

1. Hegi G. Illustrierte Flora von Mitteleuropa. 1964. Vol. 4(3). Pp. 2306-2327.

2. Войткевич С.А. Эфирные масла для парфюмерии и ароматерапии. М., 1999. 329 с.

3. Davis P.H. Flora of Turkey and East Aegean Islands, Edinburg: University Press, 1982. 947 p.

4. Муртазалиев Р.А. Конспект флоры Дагестана. Т.ІІІ. Махачкала, 2009. 304 с.

5. Satil F., Dirmenii T., Tümen G. Natural situation of commercial Satureja species in Turkey // 16 National Congress of Biology (September 1-7, 2002). Malatya, Turkey, 2002. Pp. 120-126.

6. Гладышева О.В., Олейникова Е.М. Онтогенез и семенная продуктивность вида Satureja montana L. при интродукции в ЦЧР // Вестник Воронежского государственного аграрного университета. 2014. №3 (42). С. 35-40.

7. Горлачева 3.С. Особенности онтогенеза Satureja montana L. Subsp. montana и Satureja montana L. Subsp. Variegata (Host) Bell. В условиях степной зоны Украины // Промышленная ботаника. 2013. Вып. 13. С. $280-287$.

8. Железняк Т.Г., Ворнику 3.Н., Тимчук К.С. Чабер горный - источник биологически активных веществ // Биологически активные вещества растений - изучение и использование : материалы Международной научной конференции 29-31 мая 2013 г. Минск, 2013. С. 98-99.

9. de Oliveira Th.L., de Araújo Soares R., Ramos E.M. et al. Antimicrobial activity of Satureja montana L. essential oil against Clostridium perfringens type A inoculated in mortadella-type sausages formulated with different levels of sodium nitrite // International Journal of Food Microbiology. 2011. Vol. 144. Pp. 546-555.

10. Mihajilov-Krstev T., Radnović D., Kitić D. et al. Chemical composition, antimicrobial, antioxidative and anticholinesterase activity of Satureja montana L. ssp montana essential oil // Cent. Eur. J. Biol. 2014. Vol. 9. N7. Pp. 668-677.

11. Палий А.Е., Хлыпенко Л.А. Летучие соединения водно-этанольного экстракта Satureja montana L. // Фармация и фармакология. 2014. №6 (7). С. 22-24.

12. Svoboda K.P., Hay R.K.M., Waterman P.G. Growing summer savory (Satureja hortensis) in Scotland: Quantitative and qualitative analysis of the volatile oil and factors influencing oil production // Journal of the Science of Food and Agriculture. 1990. Vol. 53. N2. Pp. 193-202.

13. Müller K., Riebau F., Berger B., Yegen O. Chemical Composition and Fungitoxic Properties to Phytopathogenetic Fungi of Essential Oils of Selected Aromatic Plants Growing in Turkey // J. Agric. Food Chem. 1995. N43. Pp. 2262-2266.

14. Во Тхингок Х.А., Джалилов Ф.С. Антибактериальная активность эфирных масел и их использование для обеззараживания семян капусты от сосудистого бактериоза // Известия ТСХА. 2014. Вып. 6. С. 59-68.

15. Зубарев А.В., Спиридович Е.В. Использование эфирных масел растений для профилактики шистосомного церкариоза // Биологически активные вещества растений - изучение и использование : материалы Международной научной конференции 29-31 мая 2013 г. Минск, 2013. С. 102-103.

16. Вагабова Ф.А., Мусаев А.М., Алибегова А.Н, Раджабов Г.К., Гасанов Р.З., Гусейнова З.А. Изучение суммарного содержания флавоноидов и антиоксидантной активности надземной части Saturea subdentata Boiss., произрастающей в условиях Дагестана // Фундаментальные исследования. 2013. №4-1. С. 103-107.

17. Государственная Фармакопея СССР. Общие методы анализа. Лекарственное растительное сырье. М., 1989. $400 \mathrm{c}$.

18. Adams R. Essential Oil Components by Quadrupole GC/MS, Allured Publishing Corp., Carol Stream, IL. 2001.

19. Aliev A.M., Radjabov G.K., Musaev A.M. Dynamics of supercritical extraction of biological active substances from the Juniperus communis var. Saxatillis // The Journal of Supercritical Fluids. 2015. Vol. 102. Pp. 66-72.

20. Aliev A.M., Radjabov G.K., Stepanov G.V. Component fnflysis of supercritical $\mathrm{CO}_{2}$ extract of Juniperus oblonga M.-Bieb fruits // Russian Journal of Physical Chemistry B. 2013. Vol. 7. N7. Pp. 795-801.

21. Королюк Е.А., Ткачёв А.В. Химический состав эфирного масла двух видов полыни: Artemisia frigida и Artemisia argyrophylla // Химия растительного сырья. 2009. №4. С. 63-72.

22. Ткачев А.В. Исследование летучих веществ растений. Новосибирск, 2008. 969 с.

Поступило в редакичию 1 июля 2016 г.

После переработки 14 октября 2016 г. 
Radzhabov G.K. ${ }^{1}$, Aliev A.M. ${ }^{1,2}$, Vagabova F.A. ${ }^{l}$, Musaev A.M. ${ }^{l}$ COMPONENT COMPOSITION OF ESSENTIAL OIL OF SATUREJA SUBDENTATA BOISS. FROM NATURAL AND INTRODUCTION POPULATIONS OF THE FLORA DAGESTAN

${ }^{l}$ Mountain Botanical Garden of the Russian Academy of Sciences, Dagestan Scientific Center, ul. Yaragskogo, 75, Makhachkala,367000 (Russia), e-mail: chemfarm@mail.ru

${ }_{2}^{2}$ Institute of Physics, Dagestan Scientific Center, Russian Academy of Sciences, ul. Yaragskogo, 94, Makhachkala, 367000 (Russia), e-mail: aslan4848@yahoo.com

The taxonomic position of investigated species and its fragmented habitat together with polymorphic species within its natural propagation is of interest to study the variability of the trends on the component composition of essential oils along environmental gradients.

Based on the fact that Dagestan is part of the areal of this species previously to not been studied for the composition of the essential oil component the aims of the present study was to gain an understanding of the component of essential oil of a "typical" population Satureja subdentata Boiss. from the middle mountains.

The essential oil isolated from the aerial parts of S. subdentata by hydrodistillation was analyzed by GC-MS. Fifty three were identified from of total sixty one compounds.

Thus, the observed reduction of monoterpenes and derivatives thereof and sesquiterpenes and derivatives thereof increase when compared with the natural sample (Kuppinsky Pass,1000 m above sea level) with their samples to Gunibsky (1730 $\mathrm{m}$ above sea level) and Tsudaharsky (1100 $\mathrm{m}$ above sea level) experimental base. Noted differently directed action of altitude of raw material gathering places on above sea level on quantitative content of individual essential oil components.

Keywords: Satureia subdentata Boiss, essential oil, Clevenger apparatus, gas chromatography-mass spectrometry.

\section{References}

1. Hegi G. Illustrierte Flora von Mitteleuropa, 1964, vol. 4(3), pp. 2306-2327.

2. Voitkevich S.A. Efirnye masla dlia parfiumerii i aromaterapii. [Essential oils for perfumes and aromatherapy]. Moscow, 1999, 329 p. (in Russ.).

3. Davis P.H. Flora of Turkey and East Aegean Islands, Edinburg: University Press, 1982, 947 p.

4. Murtazaliev R.A. Konspekt flory Dagestana. [Synopsis of the flora of Dagestan]. Makhachkala, 2009, vol. III, 304 p. (in Russ.).

5. Satil F., Dirmenii T., Tümen G. 16 National Congress of Biology (September 1-7, 2002), Malatya, Turkey, 2002, pp. $120-126$.

6. Gladysheva O.V., Oleinikova E.M. Vestnik Voronezhskogo gosudarstvennogo agrarnogo universiteta, 2014, no. 3(42), pp. 35-40. (in Russ.).

7. Gorlacheva Z.S. Promyshlennaia botanika, 2013, no. 13, pp. 280-287. (in Russ.).

8. Zhelezniak T.G., Vorniku Z.N., Timchuk K.S. Biologicheski aktivnye veshchestva rastenii - izuchenie $i$ ispol'zovanie: materialy mezhdunarodnoi nauchnoi konferentsii 29-31 maia 2013. [Biologically active substances of plants - the study and use of: materials of the international scientific conference 29-31 May 2013]. Minsk, 2013, pp. 98-99. (in Russ.).

9. de Oliveira Th.L., de Araújo Soares R., Ramos E.M. et al. International Journal of Food Microbiology, 2011, vol. 144, pp. 546-555.

10. Mihajilov-Krstev T., Radnović D., Kitić D. et al. Cent. Eur. J. Biol., 2014, vol. 9, no. 7, pp. 668-677.

11. Palii A.E., Khlypenko L.A. Farmatsiia i farmakologiia, 2014, no. 6 (7), pp. 22-24. (in Russ.).

12. Svoboda K.P., Hay R.K.M., Waterman P.G. Journal of the Sci. of Food and Agr., 1990, vol. 53, no. 2, pp. $193-202$.

13. Müller K., Riebau F., Berger B., Yegen O. J. Agric. Food Chem., 1995, no. 43, pp. 2262-2266.

14. Vo Tkhingok Kh.A., Dzhalilov F.S. Izvestiia TSKhA, 2014, no. 6, pp. 59-68. (in Russ.).

15. Zubarev A.V., Spiridovich E.V. Biologicheski aktivnye veshchestva rastenii - izuchenie i ispol'zovanie: materialy mezhduna-rodnoi nauchnoi konferentsii 29-31 maia $2013 \mathrm{~g}$. [Biologically active substances of plants - the study and use of: materials of the international scientific conference 29-31 May 2013]. Minsk, 2013, pp. 102-103. (in Russ.).

16. Vagabova F.A., Musaev A.M., Alibegova A.N, Radzhabov G.K., Gasanov R.Z., Guseinova Z.A. Fundamental'nye issledovaniia, 2013, no. 4-1, pp. 103-107. (in Russ.).

17. Gosudarstvennaia Farmakopeia SSSR. Obshchie metody analiza. Lekarstvennoe rastitel'noe syr'e. [State Pharmacopoeia of the USSR. General methods of analysis. Herbal raw material]. Moscow, 1989, 400 p. (in Russ.).

18. Adams R. Essential Oil Components by Quadrupole GC/MS, Allured Publishing Corp., Carol Stream, IL. 2001.

19. Aliev A.M., Radjabov G.K., Musaev A.M. The Journal of Supercritical Fluids, 2015, vol. 102, pp. 66-72.

20. Aliev A.M., Radjabov G.K., Stepanov G.V. Russian Journal of Physical Chemistry B, 2013, vol. 7, no. 7, pp. $795-801$.

21. Koroliuk E.A., Tkachev A.V. Khimiia rastitel'nogo syr'ia, 2009, no. 4, pp. 63-72. (in Russ.).

22. Tkachev A.V. Issledovanie letuchikh veshchestv rastenii. [Study of volatile plant materials]. Novosibirsk, 2008, 969 p. (in Russ.).

Received July 1, 2016

Revised October 14, 2016

\footnotetext{
* Corresponding author.
} 